

\title{
Archaeological Record in Karst Landscape: The Travels of Materialities
}

\author{
Neda Kulenović Ocelić
}

DOI:10.17234/9789531757799.6

\author{
Independent researcher \\ Ulica Andrije Hebranga 21 \\ HR-23 000 Zadar, Croatia \\ nedaocelic@gmail.com
}

The paper explores the materiality of the landscape in a very specific Dinaric karst setting. A karst environment is specific in the sense that it is characterized by materialities and relational properties rather different than other geomorphological contexts. The materiality of karst and what it implies is often overlooked in archaeology. Hence, the constitution of the archaeological record in karst is treated as a disembodied set of highly generalized and reductive processes.

The most prominent feature of karst as an archaeological environment is the lack of a sub-surface context and almost complete dominance of surface structures. Surface structures enable direct interaction with past landscapes which thus always already participate in the constitution of landscape as synchronous elements in a taphonomic process. Thus, the emergence of the karst landscape involves properties of various materialities which constantly interact with each other only to produce new contexts for new dynamics.

The interwoven properties of various materialities include both human and non-human actors and actants. The elements in the taphonomic processes were identified and studied as to how various materialities interact through their properties to constitute new assemblages. The case studies selected to demonstrate these issues are considerably different in terms of materialities they entail.

\section{Introduction}

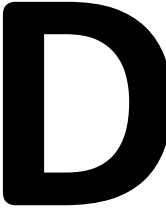

inaric karst is an emblematic form of the landscape for a larger part of Croatia and southeastern Europe. The distinctiveness of karst as an environment is reflected in the specificity of archaeological remains and in the practice of conducting archaeological research. Although the tradition of archaeological research in Croatia is long (especially in coastal areas) the archaeological remains were not discussed in relation to their specificities and idiosyncrasies. The topography of archaeological sites presented a satisfactory level of data acquisition and analysis within the context of the dominant culture-historical paradigm. The perspective introduced by the landscape archaeology demands a more holistic approach to archaeological remains which would consider the landscape transformations in the context of the immediate materiality of this particular archaeological environment - the karst. Issues discussed in this paper are the result of a field survey conducted since 2016 on southeastern Velebit and karst plain - typical Dinaric karst areas. The research may have begun as a field survey project with proclaimed aims and expected results appropriate for such an endeavor. However, during the course of actually conducting the survey, it became obvious that the survey is, in fact, a context for reflection on and reconceptualization of standard archaeological operative concepts. The focus of the paper is primarily the "nature" of the archaeological record in a karst land- 
scape defined as an archaeological environment. Karst areas are particularly appropriate to demonstrate that the constitution of the archaeological record is contingent upon the material properties of a particular environment and not universal laws external to the dynamics in a particular landscape.

\section{Karst as an Archaeological Environment}

The creation of archaeological knowledge in Croatia has a long-standing tradition indeed. Traditional, culturehistorical paradigm was instrumental in creating that knowledge. The practice of this discursive formation is reflected in the detailed knowledge on sites topography and characteristic forms of material culture. These forms of knowledge are self-sufficient since this type of information is simultaneously data and an end result of scholarly enquiry culminating in the definition of archaeological cultures (Kulenović 2013). Issues such as the modes of visibility and preservation of sites, their spatial distribution, the representativeness of data etc. are simply beyond the horizon of what counts as knowledge in archaeology in Croatia. Karst areas are not an exception here and the same reduction of vast complexities to mere essentialized identities was and still is the current state of affairs in archaeological scholarship in Croatia.

Neothermal Dalmatia Project (NDP) (Chapman et al. 1996) offered a significant change of perspective. The project was, until recently, mostly ignored in Croatian archaeology. Nevertheless, it constitutes an important shift in archaeological reasoning and an important departure point for further research in this area. The NDP provided one of the first glimpses of processual thought in Croatian archaeology. Rather than an emanation of essentialized, bounded entities, the material culture is constituted as an indicator of social complexity levels as well as a basis for analyzing relations between land use and settlement patterns. The foundation of this research was a sampled field survey. Consequently, the research area was categorized and analyzed according to multiple criteria. The karst areas i.e. the area of limestone ridges of Ravni Kotari in Zadar hinterland was designated as the "zone of preservation". The features were preserved in this zone because their material characteristics rendered them unaffected by all forms of cultivation (Chapman et al. 1987: 136). Accordingly, the research area discussed in this paper fits the profile of a "zone of preservation" category although the geological characteristics of the respective areas are somewhat different.

The categories "zone of preservation/destruction" are defined in relation to the kind and the intensity of agriculture as the most prominent transformation factor in plough zone areas (Taylor 1971, cited in Chapman et al. 1987: 136). These categories are rather inappropriate for the research area and karst in general because the longterm subsistence strategies throughout history in these areas were pastoralism/nomadic pastoralism. The fact of the matter is that cultivation, as a primary transformation factor is practically non-existent in karst areas. Such activities are concentrated exclusively on smaller areas of dolines and poljes. Therefore, it appears ill-advised to characterize areas according to transformation factors which are not operating in that particular area. Having this in mind, the initial categorization of types of archaeological remains, according to the modes of visibility and preservation, was first carried out within the NDP. Three categories of archaeological sites were defined: monuments or standing monuments, findspots and single finds (Chapman et al. 1987; 1996). The designation of archaeological record in karst as the monument is reminiscent of the oldest notions of archaeological sites as "discrete and obvious" (monument model, Banning 2002: 13) and we might add isolated, singular and romanticized. We may also note that the suggested categories are not defined using a common criterion. The monuments are as real as possible while findspots and single finds reflect some other reality than their own. The notion of a monument does not appear to meet the standards of what constitutes an analytical concept, at least not according to standards espoused in archaeology from the days of processual archaeology onwards. Rather, it is a purely designative concept where it is assumed that mere naming or typological categorization fully exhausts the purpose of scholarship. The designation of archaeological remains as monuments renders the landscape under study ahistorical and static in nature and reduces it to a "timeless Mediterranean landscape" (Barker 2005: 47, Fig. 3.1). To be fair, the term monument may have a "practical" etymology since a large number of sites in karst, a vast majority even, is visible as or predominantly as surface features. Nevertheless, the implication of such categorization (Chapman et al. 1987; 1996) is that practically all archaeological sites in karst fall under the rubric of a monument which is hardly a discerning classification. The classification was probably informed by the situation in temperate areas since the preservation of sites in the "monument form" is an exception in such areas rather than the rule. Furthermore, karst is an archaeological environment all of its own and what appear to be the rules may not apply, generalized as they are on the basis of other areas. Therefore, rather than viewing karst as a backdrop to monuments which happen to populate the area, it appears that we would do better to view karst with the full appreciation of its individuality and particularity. 
The preservation and the mode of visibility of sites in karst areas is primarily contingent upon the very materiality of such landscapes. Simply put, this refers to the way of life in the landscape, the use of landscape and natural and geological processes which form the landscape as a network of mutually interacting processes. For starters, we must unequivocally declare that the karst landscape is "built" from limestone. Archaeological record in such an environment is commonly not expressed in the form of relations between surface and sub-surface record and represented by finds, as may be the case in the majority of areas where the practices of field survey were developed. The basic constitutive element of a karst landscape is limestone rock rather than any form of soil. Therefore, it appears pointless to define karst in negative terms, as a landscape lacking a certain quality simply because the default for all things survey was defined in areas with different characteristics. To bring the point home, the differentia specifica of karst landscapes is extremely low soil coverage. Areas which contain soil in karst landscapes are places of extremely concentrated activities and they present an exception rather than the rule. Therefore, the soil is comparatively inconsequential for material relations in the karst landscape and archaeology.

The basic forms of practices in karst are adding and subtracting or removing the stone. A crucial practice in karst landscape is a clearance of arable portions of land and as a direct result of this practice boundary walls and various clearance features are being built. Limestone rock is the very fabric of karst and as such the structures built of stone are very durable. Past practices are materialized in stone. Therefore, the materiality of the landscape has an active role in the preservation and destruction of archaeological features. As such, archaeological features in karst are preserved and visible mostly as surface structures made of stone. Consequently, past material practices have become a permanent presence in landscape topography and its surface.

Since archaeological features in karst are preserved and visible mostly as surface structures, the researchers are always in direct contact with them. Therefore, the archaeological record is detected and documented in its immediate materiality. The contact or interaction between the researcher and the researched is not mediated through the relationship of subsurface and surface context. The problematics of field surveying in karst, as well as methodological, epistemological and ontological implications of such research, require a distinct elaboration and formulation. These features, characteristics and the implications of the archaeological record in karst have further enabled the rethinking of the common notions such as the nature of the archaeological record, the constitution of the landscape and research in general.

\section{On the Archaeological Record}

The practice of archaeology was constituted by various concepts which simultaneously determined different research methods. Several crucial notions were instrumental in constituting the modern archaeological reasoning. Perhaps the most important departure point was the introduction of systems theory in archaeology. This repositioned the scale of archaeological research from a single site to regional level and enabled the development of landscape archaeology as a separate discipline with a distinctive categorical apparatus (Novaković 2003: 135-138), which still figures as a dominant paradigm in the practice of archaeological survey today.

Notions such as Binford's definition of archaeological record as the static reflection of dynamic system and the assumption that the spatial distribution of archaeological finds reflects activities in the past (Binford 1981: 197-199; 1983: 19; followed up by Schiffer 1972; 1975) have expanded the perspectives of the archaeological research and generated new discussions and development of new disciplines in archaeology. Operative concepts in landscape archaeology are directly contingent upon these initial assumptions. The site formation process is perhaps the most important among them. The significance of this concept for field survey methodology in particular, cannot be overstated. Schiffer (1972; $1975 ; 1983$; 1996) based the concept of formation process on the differentiation between and the constitution of a systemic (dynamic) and archaeological (static) context. These contexts are affected by transformation processes, namely, non-cultural and cultural transforms (Ibidem).

The archaeological context understood as static is at the very core of archaeology and embodied in the practice of archaeology through research strategies and methods. The positioning of the archeological context in the realm of the static, as opposed to systemic or dynamic, constitutes the binary opposition based on the Cartesian worldview of dichotomies between subject - object, mind and body. The archaeological context is positioned in the realm of the body, the object, the material, the passive. By positioning the archaeological record in the realm of the object, it is constituted as an entity or a set of entities functioning according to logical rules, mechanisms and laws. Such a nomothetic approach suggests that it is not only possible but necessary to define and 
apply the appropriate methodological procedures in order to discover and define the underlying processes in the constitution of the archaeological record. (Thomas 2001: 165-167; 2004: 55-77).

The Cartesian logic is followed by further fragmentation into independent, separate and opposed categories of cultural and non-cultural formulated as constitutive formation mechanisms. These mechanisms are formulated as cultural and non-cultural formation and transformation processes. The cultural transformation process is defined as the process of deposition or creation, whereas the non-cultural as the process of post-depositional modification and destruction. The essentialization of the archaeological record is embodied in the depositional mode which stands in opposition with the post-depositional process of external forces of non-cultural transformations. Constituted as an object, the archaeological record is always already reconstituted as an object by the application of the methods based on law-like principles of assumed regularities. The examples of such reasoning include the discussion of identifying the transformation processes which created the surface finds distribution patterns as well as their relationship with the subsurface patterns, the reconstruction of their relationship, the methodology of data collection, sampling strategies etc.

The conceptualization of archaeological record as a string of mechanistic processes is rooted in a system of values embodied in a desire for boundedness, originality and preservation. ${ }^{1}$ Defining and identifying the transformation processes is predicated upon the belief and desire for the existence of a "golden age" of originality, a state we must strive to recapture and, in a sense, turn the proverbial clock around.

The dual ontology represents the very essence of the Cartesian perspective and is reflected in the representational mode (Thrift 1996). The representational mode ${ }^{2}$ is based on the notion of separateness and it is manifested in the projections of the subject on the categories of object. Cartesian dual ontology can be substituted for a relational ontology defined within the Actor Network Theory (Latour 1993) and further elaborated within the notion of hybridity (Whatmore 1999). The concept of hybridity is particularly relevant for the approach proposed in this paper. The implications of such an approach would be that archaeological record is a material process, irreducible to any one nod in that process. Therefore, a consecutive succession of transforming events eroding the original to oblivion should be substituted for a more nu-

1 The underlying assumptions are demonstrated in the epic Pompeii premise discussion (Binford 1981; Schiffer 1985).

2 Lucas (2001: 149) describes Binford's concepts of static and dynamic as a representational model. anced approach where various affordances of material actors and actants affect a constant flow of materialities in an on-going process of change (Ibidem).

Therefore, rather than a set of superimposed cultural and non-cultural mechanical processes which are at work on the static archaeological record, as suggested by the Cartesian perspective, the constitution of the archaeological record is a process involving the very material properties of actors and actants in a relational field. Various actors and actants are mutually constitutive through continuous material engagement of their capacities, a state Sarah Whatmore defined and elaborated as hybridity (Whatmore 1999). The concept of a hybrid is not only characterized by relational modality but also by a post-humanistic perspective of the decentralized subject and agency. Relational ontology is based on the active relationship of human and non-human or agents and actants. The affordances of actors are their agencies and agency, on the other hand, is their interconnecting link. The interaction of actor properties, rather than their fixed material characteristics, constitutes the hybrid capacity. Agency is thus posited as decentralized because everyone and everything has it. Hybrid is never static but is always in the state of becoming through interactions of actor's agencies (Ibidem). Naturally, the concept of hybridity is not some sort of a replacement for mechanical processes but rather a radical reconceptualization of the archaeological record. The Cartesian dual ontology posits the archaeological record as static, cultural or naturalistic (in a sense Lucas used the term, 2001: 151-152). The concept of hybridity (Whatmore 1999) suggests that all actors and actants involved in a relational field act through their capacities or material affordances. This constant flow of mutually constituting affordances and affects is what constitutes the archaeological record. Everything is always already moving, changing and on their way to become something different. The ideas of originality and preservation are simply redundant because there never was the original record (systemic or otherwise) to begin with: only a constant flow of various materialities affecting each other to produce new conditions for new flows in an ever ongoing non-directional process.

\section{Archaeological Record in Karst}

This section will present examples of archaeological sites in karst which were discovered and documented during field survey: a path and deposits on structures generated thorough field clearance activities. Each of these examples represents common features in karst: paths are, by far, the most common archaeological feature and clearance activities are one of the most common practices in 


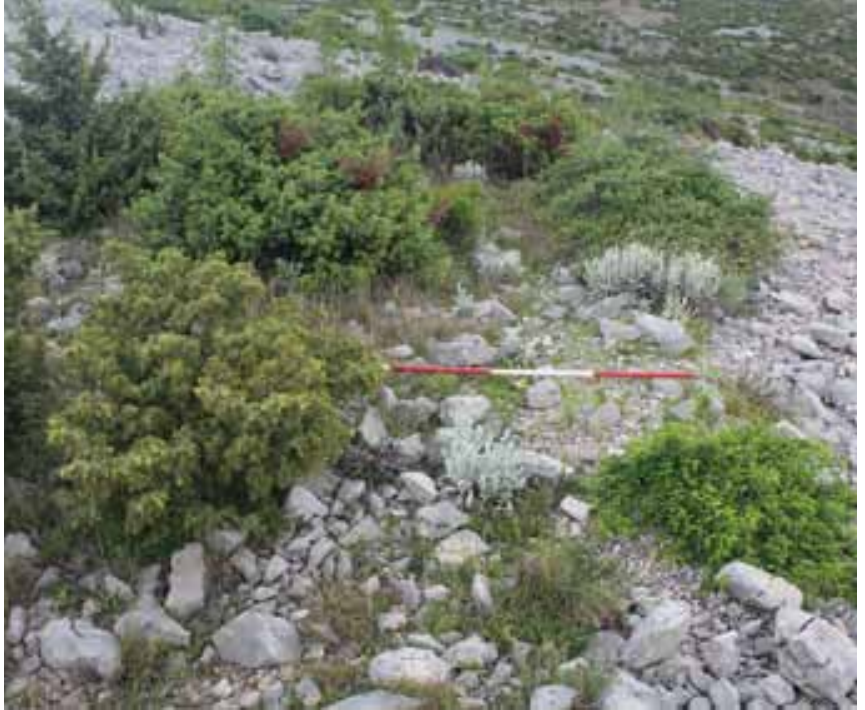

FIGURE 1. The path on slopes of Zrmanja canyon (photo: author).

karst agriculture. Furthermore, the examples presented here illustrate the dynamic interaction of cultural and non-cultural, human and non-human.

The path described in the following section is a vivid example of various materialities at work in a karst environment (Fig. 1.). The feature interpreted as a path is placed on the slopes of the Zrmanja canyon (Fig. 2.). The structure is formed as a negative by clearing and extracting the limestone bedrock, thus creating a flat and uneven linear surface $2.5 \mathrm{~m}$ wide. The environment at this particular place is characterized by exposed rock surface, complete lack of soil and well-developed karst surface features such as deep grikes. The vegetation cover is extremely scanty and almost completely limited to the structure. Soil coverage displays similar characteristics as the vegetation cover. It is exclusively concentrated on the structure surface. A rather large quantity of surface finds was recovered scattered at the slopes below the path. The finds featured only fragments of pottery which were distributed in small concentrations. Based on the technological characteristics, the finds can be roughly dated to Early Modern Period. Although some sections of the structure could not be identified, the direction and topography suggest that the path connected two particular points in the landscape: a well placed in a gully and a multiperiod hillfort site Šibenik.

The practice of field survey and subsequent interpretations commonly include questions concerning the proper order of transformation factors affecting changes in the landscape (for instance: Gaffney et al. 1991). Actually, our entire investigative mindset is predicated upon the drive to neatly dissect the causative relations in the taphonomic process (Schiffer 1972; 1975; 1983; 1996). Naturally, the underlying assumption is that history progresses from some original state to the present.

The problem we are faced with includes not only the history of events leading to the present but rather the present is as much part of the history as is the past. Therefore, the structure as it is visible to us today is a result of various material agencies with different temporal regimes rather than the linear sequence of superimposing events. A common place to start a taphonomic narrative would be the building of the path. However, from the land point of view, the path is not the beginning of anything. It is merely a chance occurrence enabling the accumulation of soil and the growth of vegetation - two factors facilitating the archaeological detection. Therefore, a good place to start instead might be the soil. The soil is a rare commodity indeed in karst landscapes and it never would have formed at this particular place if it were not for the other agencies at work. The paths are made for walking or rather the movement of humans and animals. However, paths are also flat surfaces (unlike the rest of the surrounding area) and such surfaces tend to accumulate the organic material carried by the wind or produced by humans and animals. The removal of the limestone bedrock and the subsequent construction of the path has altered the micromorphology and microtopography of Zrmanja canyon slopes creating a straight, cut, regular and linear flat surface. This newly created surface possesses different characteristics in the deposition regime when compared to the surrounding areas of canyon slopes and surface features such as deep grikes. The created surface has become an integral part of the landscape and an actant engaging the relational properties of humans, animals, plants and wind. Coupled with the affordances of other actors and actants, a new context was created. When archaeologists came along, a new relational layer was added constituting this particular situation as archaeological record.

The common understanding of the archaeological record is rooted in the representational model of the dynamic and the archaeological context. These contexts are changed through the work of individual events formulated as cultural and non-cultural transforms (Schiffer $1972 ; 1975 ; 1983 ; 1996)$. The example of the path demonstrates that the dichotomies such as static and dynamic, cultural and non-cultural simplify and reduce the complexities of landscape formation. The processes occurring in the landscape are treated as a sequence of singular events rather than synchronous interactions (Thomas 2001). The social practice has transformed the canyon slope by forming a flat surface. However, the 


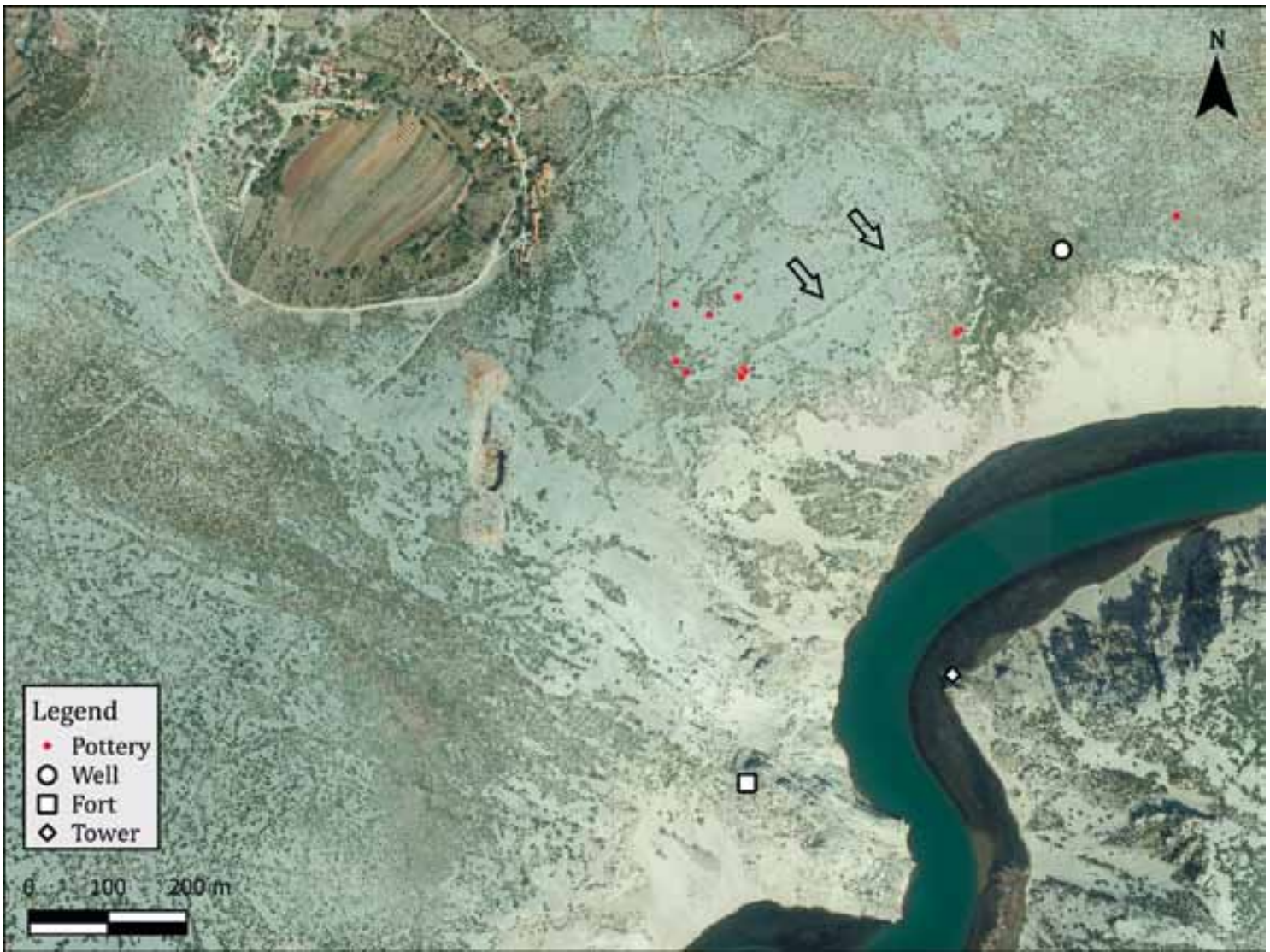

FIGURE 2. The path on slopes

of Zrmanja

canyon - marked

by arrows and

the local setting

(made by the

author, base

map: geoportal. dgu.hr).

built feature is not simply a backdrop for other developments to take place but rather it has become a new context for a relational network between living and nonliving agents. The spatial constraints of social and natural processes involving the feature are one and the same. Although the spatiality of the feature is constraining, it is by no means a defining factor. Rather, all the elements in the relational field are mutually constitutive.

The dynamic character of archaeological record may be illustrated with another example documented during the field survey. Different types of finds dated to the Roman period (tegulae, amphorae, stone blocks, mortar fragments etc.) were documented as scattered deposits on clearance features such as boundary walls and clearance cairns (Figs. 3-4). The finds represent the actual remains of a Roman villa. This type of deposit is specific for sites dated to the Roman period in karst areas. Such deposits are restricted to dolines and poljes as only arable areas. This type of site/deposit is rather rare in the study area. Their presence appears to be limited to Rovanjska, an area featuring a small cove in the Velebitski kanal.

Archaeological deposits on clearance features were presented as the latest and hitherto undiscovered transformation factor (Gaffney et al. 1991). This transformation has affected a complete dislocation of finds from their original context. The transformation factor operates on at least two levels: spatially and at the level of finds size. The researchers (Ibidem) defined a sequence of events, leading from the original or systemic context of the Roman villa to its disassembling by a cultural transformation factor. This particular factor refers to local agriculturalists who affect the archaeological record through their work. Several problems can be identified with this reasoning. The first is an unproblematic and rather arbitrary privileging of archaeological remains as if they somehow present a default everything else derives from. As discussed earlier, this reasoning is embedded in Cartesian thought where archaeological record displays a teleological trajectory from the state of completeness to the state of decay.

A perspective which conceptualizes the archaeological record as a static entity, affected and determined by external forces fails to appreciate other potential of such material-spatial expression. The deposits on clearance features may be viewed as a material expression constituted through repetitive practice rather than a transformation factor which indirectly reflects the archaeological record. The problematics presented by the deposits on 
clearance features is not reducible to land use patterns such as the preferential land use classes in the Roman period, the land division in Medieval and Early Modern period negating the Roman pattern or designating this landscape as a palimpsest.

The practice of land clearance is one of the basic longterm repetitive practices in karst which is materialized in stone. Arable land along the cove represent the material-spatial traits mobilized in the Roman world. Subsequently, the remains of the Villa at the edge of the cove slopes became an integral part of the feature and simultaneously a context for activities such as removal, separation and assembling all the while creating arable land and land division drystone walls. Parts of the Villa are actants much in the same way as the natural rock. Together they represent forms of material which in this particular socio-material context is appropriate for removal and deposition on clearance features. This is the context where the Villa is disassembled into smaller fractions and arranged into new assemblages and takes its place in the present. The life of the Villa in the present is quite literal since it takes an active part in creating land division drystone walls and constituting the social relations in the community.

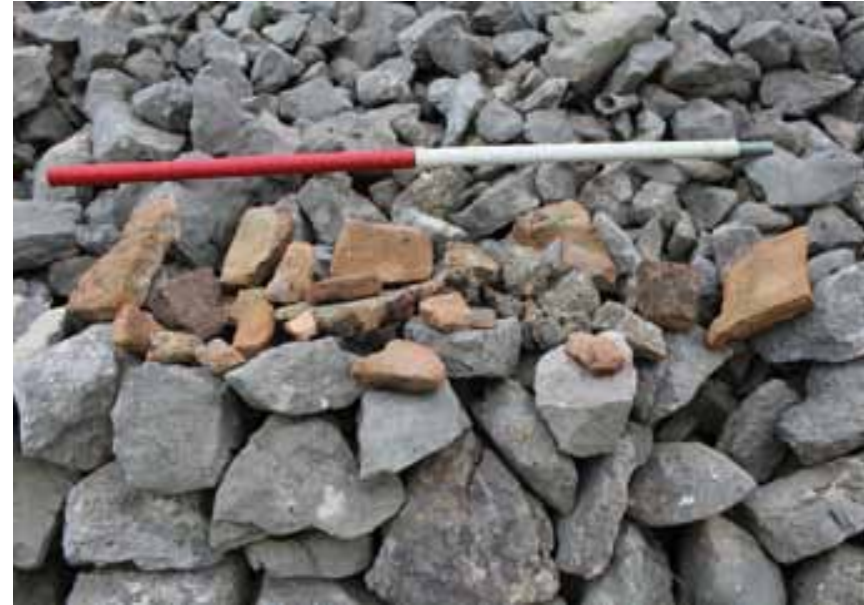

FIGURE 3. Deposits of tegulae and amphorae fragments on a stone cairn in Rovanjska (photo: author).

The archaeological record from this example can be understood as the result of material practices which are always already in the state of movement and ever emerging. These processes cannot be accounted for by the binary and opposed categories of systemic or the archaeological, cultural or non-cultural. Rather, the ar-
FIGURE 4. Spatial distribution of finds on clearance features in Rovanjska (made by the author, base map: geoportal. dgu.hr).

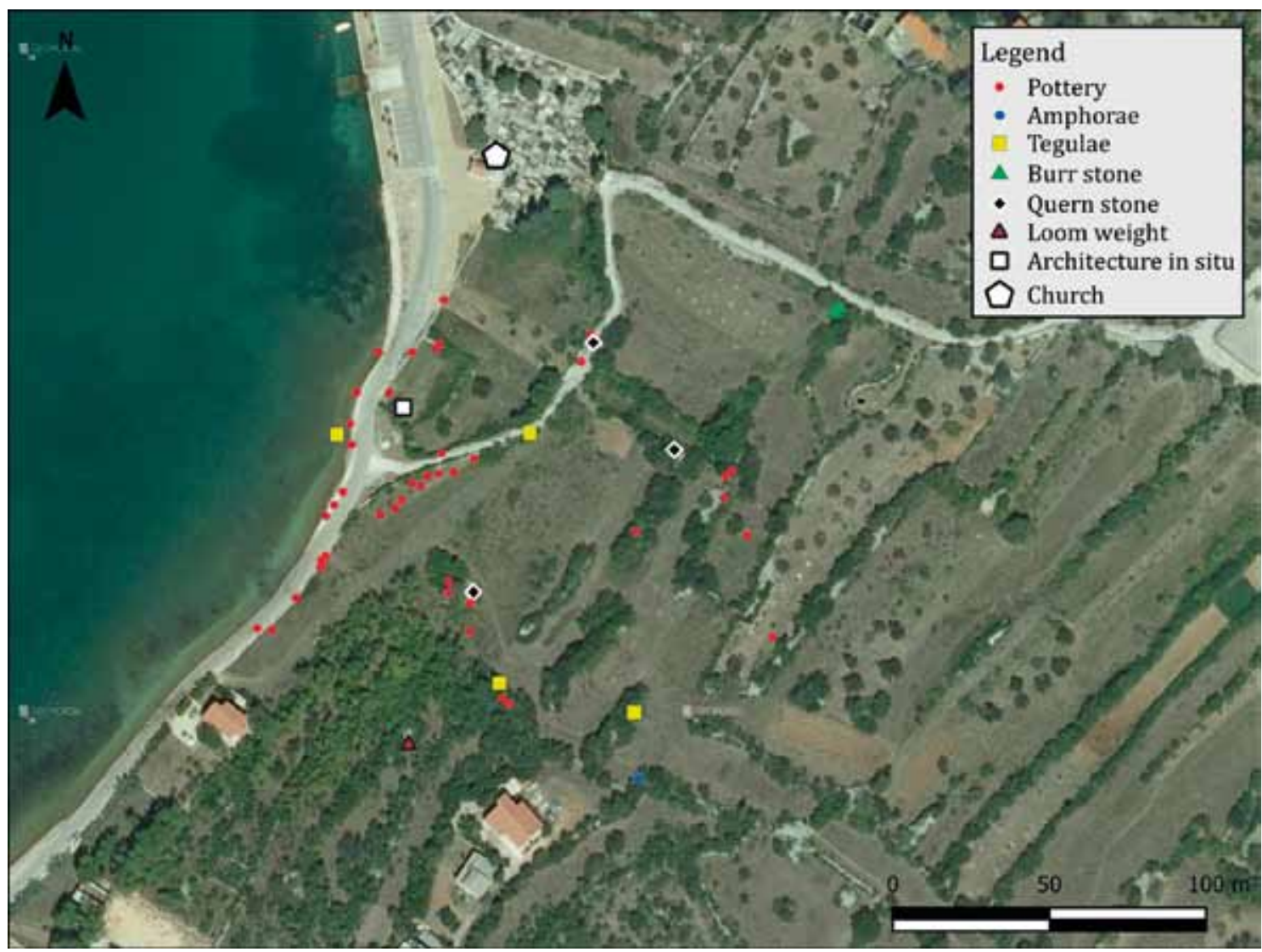


chaeological record is created by relations of affordances, properties or capacities of human and non-human actors and social practice. These notions could affect our understandings of how landscapes are formed considering the transformative nature of social practices intertwined with material and/or non-human. This example may represent a context for understanding the landscape as a relational field which is always, in Binford's (1981) terms, in a systemic context.

\section{Conclusion}

The research and interpretations presented in this paper are an attempt to highlight the materiality of the landscape by performing the research, rather than elaborate various notions and categories exclusively in discourse while being sensitive to the rhythms and processes of various material agencies acting in a karst environment. Archaeological research in Croatia displays a long tradition. Culture-historical paradigm determined the focus of research where karst was not discussed as a separate area of research. In that sense, the focus was on defining cultural groups and references to space/landscape were reduced to anthropogeographic interpretations. More recent international research projects (Chapman et al. 1996) were focused on practicing archaeology as a universal set of rules and laws which ultimately reflects a positivistic Cartesian view. Namely, this is reflected in the conceptualization of archaeological landscapes and archaeological remains in karst as a measure of the temperate areas for which the methodology and concepts were developed in the first place.

Rather than pursuing the practice of defining karst as a measure of others, this paper suggests an approach to archaeology in karst which is more attuned to the intricacies of a particular area. The purpose of the conducted field survey was, naturally, to collect archaeological data but more importantly to understand karst in its materiality - what actually constitutes karst as an archaeological environment. Čučković (2012: 269) claims that karst is not suitable for a systematic archaeological survey. This claim is not really wrong. It only treats karst in negative terms which ultimately means that karst does not meet the standards defined for completely different environments. Archaeological remains in karst are commonly represented by surface structures. Therefore, the methods which are focused on establishing the relationship between the surface and the subsurface context are simply not appropriate for a landscape where such relations are not featured in any way. Therefore, the task before us is to develop research approaches which will be in a position to fully appreciate the particularities and complexities of karst as an environment.
Archaeological survey as a discipline is dominated by a specific form of processual thinking where the essentialized archaeological record is determined by external forces, namely cultural and non-cultural transforms. This brand of reasoning assumes the existence of an original state (systemic context) which subsequently collapsed into various states of disrepair such as archaeological context or refuse. The underlying assumption is that the original context was destroyed by a linear sequence of superimposed events. This approach fails to appreciate the material affordances of all actors and actants in a relational field. The archaeological record is neither destroyed nor does it follow a linear, teleological path. Rather, the constitution of the archaeological record involves the engagement of various material capacities.

Karst appears to be a particularly suitable context for contemplating issues such as materiality and the constitution of the archaeological record. Moreover, it appears to positively resist positivistic reasoning by virtue of its very materiality. The landscape which is built almost exclusively of surface structures and durable materials represent a context for establishing a direct relationship with the "object of study". The "object" is absolutely unmediated through the approximated relations of surface and subsurface contexts. The examples presented in this paper demonstrate the inseparable and intertwined nature of the cultural and natural where the affordances of the material, including both living and non-living entities, facilitate the constitution of an ever-emerging landscape.

The notions elaborated in this paper could affect our understanding of how landscapes are formed considering the transformative nature of social practices intertwined with material and or non-human.

\section{Acknowledgements}

This work has been supported in part by Croatian Science Foundation under the project "Cultural Landscape - A Model for Valorisation, Protection, Management and Use of Cultural Heritage" - ProHeritage (UIP-2017-052152). The author would like to extend her sincere gratitude to colleagues Martina Dubolnić Glavan, Ivan Huljev, Igor Kulenović, Vedrana Glavaš and Šime Vrkić whose help was extremely helpful during field survey and Dimitrij Mlekuž whose comments were invaluable for the completion of this text. 


\section{References}

Banning, E. B., 2002. Archaeological Survey, Springer, New York.

Barker, G., 2005. Agriculture, Pastoralism, and Mediterranean Landscapes in Prehistory, In: E. Blake and A. B. Knapp (eds.), The Archaeology of Mediterranean Prehistory, Blackwell Publishing, Malden, 46-76.

Binford, L. R., 1981. Behavioral archaeology and the "Pompeii premise", Journal of Anthropological Research 37 (3), 195-208.

Binford, L. R., 2002. (1983.) In Pursuit of the Past: Decoding the Archaeological Record, University of California Press, Berkeley-Los Angeles-London.

Chapman, J. C., R. S. Shiel and Š. Batović, 1987. Settlement Patterns and Land Use in Neothermal Dalmatia, Yugoslavia: 1983-1984 Seasons, Journal of Field Archaeology 14 (2), 123-146.

Chapman, J. C., R. S. Shiel and Š. Batović, 1996. The Changing Face of Dalmatia: Archaeological Studies in a Mediterranean Landscape, Leicester University Press, London.

Čučković, Z., 2012. Metodologija sustavnog terenskog pregleda: primjer istraživanja zapadne Bujištine (Istra), Opuscula Archaeologica 36, 247-274.

Gaffney, V. L., J. Bintliff and B. Slapšak, 1991. Site Formation Processes and the Hvar Survey Project, Yugoslavia, In: A. J. Schofield (ed.), Interpreting Artefact Scatters: Contributions to Ploughzone Archaeology, Oxbow Monograph 4, Oxford, 59-77.

Kulenović, I., 2013. Materijalna kultura, značenje i praksa, Naklada Slap, Jastrebarsko.

Latour, B., 1993. We Have Never Been Modern, Brighton, Harvester Wheatsheaf.

Lucas, G., 2001. Critical Approaches to Fieldwork, Contemporary and Historical Archaeological Practice, Routlege, London-New York.
Novaković, P. 2003. Osvajanje prostora: razvoj prostorske in krajinske arheologije, Filozofska fakulteta, Ljubljana.

Schiffer, M. B., 1972. Archaeological Context and Systemic Context, American Antiquity 37 (2), 156-165.

Schiffer, M. B., 1975. Archaeology as Behavioral Science, American Anthropologist 77 (4), 836-848.

Schiffer, M. B., 1983. Toward the Identification of Formation Processes, American Antiquity, 48 (4), 675-706.

Schiffer, M. B., 1985. Is There a "Pompeii Premise" in Archaeology?, Journal of Anthropological Research 41 (1), 18-41.

Schiffer, M. B., 1996. Formation Processes of the Archaeological Record, University of Utah Press, Salt Lake City.

Taylor, C. C., 1971. The Study of Settlement Patterns in Pre-Saxon Britain, In: P. J. Ucko, R. Tringham and G. Dimbleby (eds.), Man, Settlement and Urbanism, Duckworth, London, 109-113.

Thomas, J., 2001. Archaeologies of Place and Landscape, In: I. Hodder (ed.), Archaeological Theory Today, 165-186.

Thomas, J., 2004. Archaeology and Modernity, Routledge, London.

Thrift, N., 1996. Spatial Formations, Sage, London.

Whatmore, S., 1999. Hybrid geographies: Rethinking the "Human" in Human Geography, In: D. Massey, J. Allen and P. Sarre (eds.), Human Geography Today, Polity Press, Cambridge, 22-39. 